\title{
Insurance Payer Status and Race Explains Much of the Variability in Colorectal Cancer Survival
}

\author{
Timothy L. Fitzgerald ${ }^{*}$, Cary Suzanne Lea ${ }^{2}$, Prashanti M. Atluri ${ }^{3}$, Jason Brinkley4, \\ Emmanuel E. Zervos ${ }^{1}$ \\ ${ }^{1}$ Brody School of Medicine, Division of Surgical Oncology, East Carolina University, Greenville, USA \\ ${ }^{2}$ School of Public Health, East Carolina University, Greenville, USA \\ ${ }^{3}$ Division of Medical Oncology, East Carolina University, Greenville, USA \\ ${ }^{4}$ Department of Biostatistics, College of Allied Health Sciences, East Carolina University, Greenville, USA \\ Email: ${ }^{*}$ fitzgeraldt@ecu.edu
}

Received 23 August 2014; revised 20 September 2014; accepted 15 October 2014

Copyright (C) 2014 by authors and Scientific Research Publishing Inc.

This work is licensed under the Creative Commons Attribution International License (CC BY).

http://creativecommons.org/licenses/by/4.0/

\section{Abstract}

Health care inequalities exist for patients with colon cancer. We hypothesize that factors such as payers and medical comorbidities may explain much of this inequality. Methods: Patients with colon cancer in the NCDB from 2003-2010 were identified in this study. Results: 541,649 patients were identified. Median age and survival were 68.6 years and 62.5 months. A majority of them (80.2\%) were non-Hispanic white (NHW). African American (AA) and Hispanic (HS) patients were more likely to have medicaid (MD) or be uninsured (UI) and reside in counties with lower socioeconomic status (SES). From univariate analysis, it was found that private insurance (PI) had superior survival (98.7 months) compared to MD (46.0 months), medicare (MC) (50.4 months) and UI (54.4 months). Survival was highest for HS (70.9 months) followed by NHW (63.2 months) and AA (53.0 months). Also, survival was linked to comorbidity index (CI), SES, chemotherapy, gender and surgical resection. On multivariate analysis, it was found that male (RR 1.11), SES, surgery (RR 2.29), chemotherapy (RR 1.96), CI, and stage were associated with survival. Race was a predictor of survival, with a survival advantage for HS (RR 0.87) and others (0.87) compared to NHW (1) and AA (1.2). Insurance status was strongly linked to survival. Compared to PI all other groups had poorer survival: MC RR 1.11; MD RR 1.44; and NI RR 1.42. Conclusions: Inequality in outcomes for colon cancer patients is strongly associated with race and underinsurance.

\section{Keywords}

Variability, Colorectal Cancer, Survival

\footnotetext{
${ }^{*}$ Corresponding author.
} 


\section{Introduction}

Healthcare inequalities have been associated with multiple risk factors including race, socioeconomic status (SES), geography, population density, gender and payer status [1]-[5]. Such outcomes inequalities have been noted for gastrointestinal malignancies, the most striking being associated with colorectal cancer [4]. Given that colorectal cancer represents a significant cancer burden, and interventions such as screening and surgery can decrease mortality, understanding the factors that drive inequality is imperative.

The disparity gap for colon cancer has continued to widen as deceases in mortality over the last two decades have not been equal for all groups [6] [7]. There appears to be a complex interplay of factors driving outcomes in inequality. African-American (AA) race has been the most consistently sighted factor associated with poorer outcomes [4] [6]-[8]. Such studies often do not (or cannot) account for access to care, SES, insurance or comorbidities [6] [9]-[11]. It is clear that SES, geographic, and insurance factors are also associated with outcome disparity [4] [8] [12] [13]. Accounting for these potential confounding factors unveils a more complex picture [4] [7] [8] [11] [12] [14] [15]. For example, in an equal access system, the Veteran's Administration, outcomes disparities across racial lines are significantly diminished [12] [14]. It is likely that poorer outcomes for AA are, in part, secondary to unequal use of screening, surgical resection, adjuvant therapy and appropriate follow-up [13] [16]-[20].

Although these data are intriguing, and point towards the factors associated with colorectal cancer outcome inequalities, much of the data have been derived from administrative datasets that lack key information [4] [10] [13] [20] [21]. In order to surmount these obstacles, merged datasets have been constructed with surveillance, epidemiology, and end results (SEER) or statewide cancer registries and administrative medicare data [4] [7] [16]. Such data are limited in conclusion regarding a general United States population of colorectal cancer patients, as most patients are older than 65 years and restricted to SEER (only about 17\% of the United States population) or other geographic regions. Veteran's Administration and Military Health System surmount some of these shortcomings which are limited to a small segment of the population [12] [14] [21].

Limitations in the current data regarding outcome inequalities in colorectal cancer make it imperative that further study is undertaken to better define associated factors. We hypothesized that additional data unavailable in many databases (i.e. data regarding treatment and comorbidities) would account for much of the inequalities currently documented within the literature. In order to study our hypothesis, we chose the data from the National Cancer Data Base (NCDB). The advantage of the NCDB dataset is that it represents a majority of patients diagnosed with cancer in the United States ( 70\%), documents both chemotherapy and radiotherapy treatment, and reports Charlson Comorbidity Index.

\section{Materials and Methods}

This study has been exempted from the Institutional Review Board at East Carolina University. Data use was granted via the $\beta$ user program at the NCDB. All patients with colon cancer were identified in the NCDB. The NCDB represents approximately $70 \%$ of all cancers diagnosed in the United States [22]. In order to better understand determinates of survival, data were analyzed only if Charlson Comorbidity Index (CCI) was available; this limited our analysis to patients diagnosed between 2003 and 2010. Patients were also excluded if they did not have adenocarcinoma or stage was unknown. Data obtained included region, gender, race, CCI, insurance payer and AJCC stage. Treatment variables included surgery and administration of chemotherapy. Socioeconomic variables were derived from the county level (not patient) census data on median income and percentage of high school dropout. Insurance status was defined as medicare, private, medicaid/public assistance and not insured. Race was defined as non-Hispanic White (NHW), AA, Hispanic (HS) and other for the purposes of this study.

\section{Statistical Analysis}

The differences were compared by univariate and multivariate analysis. For univariate analysis, chi-square test and students T-test were used as appropriate. Survival analysis was performed by the Kaplan-Myer method and Log rank test. Cox proportional hazard models were used to estimate the independent effects of all variables on survival. The appropriateness of proportional hazard assumptions was validated. Statistical significance was defined as $\mathrm{p}<0.05$. All analyses were performed on JMP version 17 (SAS Institute, Inc., Cary, NC). 


\section{Results}

\subsection{Population}

541,649 patients were identified. Table 1 reports the demographics of patients in the NCDB undergoing

Table 1. Demographic characteristics of colon cancer patients in national cancer data base, 2003-2010.

\begin{tabular}{|c|c|c|c|}
\hline & & Percentage/mean & Number \\
\hline \multirow[t]{9}{*}{ Location } & Atlantic & 15.6 & 84,713 \\
\hline & Great lakes & 18.8 & 101,975 \\
\hline & Midwest & 7.9 & 43,049 \\
\hline & Mountain & 3.9 & 21,056 \\
\hline & Northeast & 6.4 & 34,748 \\
\hline & Pacific & 11.2 & 60,685 \\
\hline & South & 6.6 & 35,902 \\
\hline & Southeast & 21.5 & 116,600 \\
\hline & West & 7.9 & 42,921 \\
\hline Age & & 68 & $68.4-68.5$ \\
\hline Gender & Male & 48.8 & 264,333 \\
\hline \multirow[t]{4}{*}{ Race } & White & 80.2 & 434,375 \\
\hline & Black & 11.5 & 62,495 \\
\hline & Spanish & 4.3 & 23,261 \\
\hline & Other & 4.0 & 21,518 \\
\hline \multirow[t]{5}{*}{ Insurance status } & Medicare & 57.2 & 309,976 \\
\hline & Private & 34.0 & 184,106 \\
\hline & Medicaid/public & 4.0 & 21,742 \\
\hline & Not insured & 2.9 & 15,652 \\
\hline & Unknown & 1.9 & 10,173 \\
\hline \multirow[t]{5}{*}{ County income } & $<30,000$ & 13.4 & 72,669 \\
\hline & $30,000-35,000$ & 17.5 & 94,569 \\
\hline & $35,000-45,999$ & 26.8 & 145,273 \\
\hline & $>45,000$ & 36.7 & 198,996 \\
\hline & Unknown & 5.6 & 30,142 \\
\hline Percentage of & $<14 \%$ & 32.8 & 177,687 \\
\hline High school & $14.4 \%-19.9 \%$ & 22.9 & 124,298 \\
\hline \multirow[t]{3}{*}{ Dropout } & $20-28.9$ & 22.3 & 120,924 \\
\hline & $>29 \%$ & 16.4 & 88,561 \\
\hline & Unknown & 5.6 & 30,179 \\
\hline \multirow[t]{4}{*}{ County population } & Metro & 78.1 & 423,039 \\
\hline & Urban & 13.9 & 75,038 \\
\hline & Rural & 2.0 & 10,551 \\
\hline & Unknown & 6.0 & 33,021 \\
\hline Charlson score & 0 & 70.5 & 381,925 \\
\hline
\end{tabular}




\begin{tabular}{rccc}
\multicolumn{1}{l|}{ Continued } & & & \\
\hline & 1 & 21.7 & 117,762 \\
\multirow{2}{*}{ Stage } & $\geq 1$ & 7.8 & 41,962 \\
& I & 23.8 & 128,833 \\
& II & 28.5 & 154,422 \\
Surgery & III & 27.7 & 150,308 \\
& IV & 20 & 108,086 \\
Yes & No & 92.6 & 301,584 \\
& Unknown & 7.4 & 39,878 \\
& Yes & 0.003 & 187 \\
& No & 36.2 & 196,175 \\
\hline
\end{tabular}

treatment for colon cancer from 2003-2010. The greatest number of patients came from the southeast, $21.5 \%$ $(116,600)$, the median age was 68 years; a vast majority of patients were classified as NHW $80.2 \%(434,375)$, and there was an even gender distribution. The most common insurance status was medicare (57.2\%) followed by private insurance (34\%), medicaid/public insurance (4\%) and the uninsured (2.9\%). Majority of patients came from counties with the highest median income (36.7\%) and lowest high school dropout rates (32.8\%). The majority came from metropolitan counties (population > 250,000) and had a low Charlson Comorbidity Index $(C C I)$. There was a fairly even distribution in all stages of the disease. Most patients underwent surgical resection (92.6\%) and did not receive chemotherapy (62.6\%).

\subsection{Demographic, Socioeconomic, Charlson Index, Stage and Treatment Data by Race}

Demographics: Significant variation existed in demographic, socioeconomic, stage and treatment factors when stratified by race, $\mathrm{p}<0.0001$ (Table 2). NHW patients were equally likely to be from the southeast and the Great Lakes, whereas, African-American (AA) were more likely to be from the Southeast. Hispanic (HS) patients were equally likely to be from the Southeast and Pacific, and those classified as other were more likely to be from the pacific. NHW patients were more likely to present at an older age of 69 years, compared to the other groups.

Socioeconomic: Non-Hispanic White (NHW) patients were more likely to have medicare than any other group, $60.4 \%$. AA and HS were more likely to have medicaid/public assistance or to be not insured at $15.1 \%$ and $21.4 \%$ when compared to NHW and other. NHWs and others were more likely to be from counties of $\geq \$ 45,000$ median income (39.2\% and 50.1\%) compared to AA and HS (18.6\% and 26.8\%). In addition, AA and HS were significantly more likely to be from the lowest income counties (34\% and 24.5\%). NHW and others were also more likely to reside in counties with a lower high school dropout rate when compared to AAs and HSs. AAs, HSs and Others were more likely to reside in metropolitan counties when compared to the NHW patients.

Charlson Comorbidity Index (CCI), stage and treatment: CCI 0 was fairly similar for NHW, AA and HS but slightly better for other. AA patients were more likely to present with stage IV diseases than any other group at $25.4 \%$, followed by HS (21.7\%), other (20.7\%) and NHW (17.4\%). NHW patients were slightly more likely to have surgery than any other group (93.2\%) and AAs were slightly less likely to have surgery than any other groups (89.3\%). AAs, HSs and others were more likely to receive chemotherapy than NHW patients.

\subsection{Survival}

Univariate Analysis: There was a profound association between survival and insurance status, with private insurance having a median survival of 98.7 months compared to 54.4 months for uninsured patients (Figure 1). Diminished survival for those with medicare most likely represents an expected advanced age in this group. Median survival was lowest in the mountain region and highest in the pacific region, 58.8 months vs. 70.8 
Table 2. Demographic factors by race for colon cancer patients in the NCDB, 2003-2010.

\begin{tabular}{|c|c|c|c|c|c|}
\hline Factor \% (n) & & White & Black & Spanish & Other \\
\hline \multirow[t]{9}{*}{ Location } & Southeast & $86,781(20.0)$ & 22,199 (32.5) & 5047 (21.7) & $2573(12.0)$ \\
\hline & Great lakes & 86,569 (19.9) & 11,211 (17.9) & 1598 (6.9) & 2597 (12.1) \\
\hline & Atlantic & $67,781(15.6)$ & $9618(15.4)$ & 3777 (16.2) & 3537 (16.4) \\
\hline & Pacific & $44,069(10.5)$ & $2894(4.6)$ & 5333 (22.9) & 8389 (39.0) \\
\hline & Midwest & 39,308 (9.1) & 2292 (3.7) & $308(1.32)$ & $1141(5.3)$ \\
\hline & West & $30,554(7.3)$ & $6490(10.4)$ & 4539 (19.5) & $1338(6.2)$ \\
\hline & South & $29,634(6.8)$ & $5850(9.4)$ & $122(0.52)$ & $296(1.4)$ \\
\hline & Northeast & 31,672 (7.3) & $1376(2.2)$ & 893 (3.84) & 807 (3.8) \\
\hline & Mountain & $18,007(4.2)$ & $565(0.9)$ & $1644(7.1)$ & 840 (3.9) \\
\hline \multirow[t]{2}{*}{ Gender } & Female & $221,326(51.0)$ & $33,991(54.4)$ & $11,190(48.1)$ & $10,809(50.2)$ \\
\hline & Male & 213,049 (49.0) & $28,504(45.6)$ & 12,071 (51.9) & 10,709 (4149.8) \\
\hline \multirow[t]{5}{*}{ Insurance } & Medicare & $262,246(60.4)$ & 29,226 (46.8) & $9403(40.2)$ & 9101 (42.3) \\
\hline & Private & $144,932(33.4)$ & $22,257(35.6)$ & $8132(35.0)$ & 8785 (40.8) \\
\hline & Medicaid/public & $11,315(2.6)$ & $5659(9.1)$ & $2823(12.1)$ & $1945(9.0)$ \\
\hline & Not insured & $8735(2.0)$ & $3741(6.0)$ & 2162 (9.3) & $1014(4.7)$ \\
\hline & Unknown & 7147 (1.7) & 1612 (2.6) & $741(3.2)$ & $673(3.1)$ \\
\hline Median county & $>45,000$ & 170,347 (39.2) & $11,630(18.6)$ & 6231 (26.8) & $10,788(50.1)$ \\
\hline \multirow[t]{4}{*}{ Income } & $35,000-45,999$ & 120,409 (27.7) & $13,986(22.4)$ & $5982(25.7)$ & 4896 (22.8) \\
\hline & $30,000-35,000$ & $75,650(17.4)$ & $12,284(19.7)$ & 4203 (18.1) & 2432 (11.3) \\
\hline & $<30,000$ & $43,634(10.1)$ & $21,231(34.0)$ & $5708(24.5)$ & 2096 (9.7) \\
\hline & Unknown & 24,335 (5.6) & 3364 (5.4) & $1137(4.9)$ & 1306 (6.1) \\
\hline High school & $>29 \%$ & 51,558 (11.9) & 23,336 (37.3) & $10,252(44.1)$ & 3415 (15.9 \\
\hline \multirow[t]{4}{*}{ Drop out } & $20 \%-28.9 \%$ & 93,376 (21.5) & 18,339 (29.3) & 4949 (21.3) & 4260 (19.8) \\
\hline & $14.4-19.9$ & 108,071 (24.9) & 9037 (14.5) & 3077 (13.2) & 4113 (19.1) \\
\hline & $<14$ & $157,016(36.2)$ & 8408 (13.5) & 3841 (16.5) & 8422 (39.1) \\
\hline & Unknown & $24,354(5.6)$ & 3375 (5.4) & $1142(4.9)$ & 1308 (6.1) \\
\hline \multirow[t]{4}{*}{ Population } & Metro & $329,936(76.0)$ & 53,687 (85.9) & $20,926(90.0)$ & 18,490 (85.9) \\
\hline & Urban & 67,342 (15.5) & 5107 (8.2) & $1159(5.0)$ & $1430(6.7)$ \\
\hline & Rural & 9707 (2.2) & $551(0.9)$ & $81(0.35)$ & $212(1.0)$ \\
\hline & Unknown & $27,390(6.3)$ & $3150(5.0)$ & $1095(4.7)$ & $1386(6.4)$ \\
\hline \multirow[t]{3}{*}{ Charlson index } & $>1$ & $34,629(8.0)$ & 4791 (7.7) & 1507 (6.5) & $1035(4.8)$ \\
\hline & 0 & 304,885 (70.2) & 43,485 (69.6) & $16,902(72.7)$ & $16,653(77.4)$ \\
\hline & 1 & 94,861 (21.8) & 14,219 (22.8) & 4852 (20.9) & 3830 (17.8) \\
\hline \multirow[t]{3}{*}{ Surgery } & Yes & 404,863 (93.2) & $55,774(89.3)$ & 21,199 (91.1) & 1974 (91.8) \\
\hline & No & $29,371(6.8)$ & 6693 (10.7) & 2055 (8.8) & $1759(8.2)$ \\
\hline & Unknown & $141(0.03)$ & $28(0.04)$ & $7(0.03)$ & $11(0.05)$ \\
\hline \multirow[t]{3}{*}{ Chemotherapy } & Yes & $153,378(35.3)$ & $24,511(39.2)$ & $9819(42.2)$ & 8467 (39.4) \\
\hline & No & 267,697 (61.3) & 35,485 (56.8) & $12,472(53.6)$ & $12,084(56.2)$ \\
\hline & Unknown & $13,300(3.1)$ & 2499 (4) & $970(4.2)$ & 967 (4.5) \\
\hline Age (mean) & & 69.5 & 65.4 & 63.4 & 65.1 \\
\hline \multirow[t]{4}{*}{ Stage } & I & $106,023(24.4)$ & 13,217 (21.2) & 4722 (20.3) & $4871(22.6)$ \\
\hline & II & $126,561(29.1)$ & $15,800(25.3)$ & 6425 (27.6) & $5636(26.2)$ \\
\hline & III & $119,096(27.4)$ & $17,583(28.1)$ & 7065 (30.4) & $6564(30.5)$ \\
\hline & IV & 82,695 (19.4) & 15,895 (25.4) & 5049 (21.7) & 4447 (20.7) \\
\hline
\end{tabular}


months. Women had significantly longer survival than men, 65.8 months vs. 60.2 months. County income was also significantly associated with survival, with the greatest survival in the highest income counties and a near linear decrease with county income, $\mathrm{p}<0.0001$. A similar trend was noted for the percentage of high school graduation, with a linear decrease with an increase in dropout rates. Survival was greatest for patients coming from metropolitan counties, followed by urban counties than rural counties. Not surprisingly, CCI and stage were strongly associated with survival. When stratified by race survival was greatest for other (88.8 months) followed by HS, NHW and AA at 70.9, 63.2 and 53.0, respectively (Figure 2).

Multivariate Analysis: In order to better understand the relationships between survival, patient demographics and outcomes, we performed a Cox regression analysis. As a result of the large numbers in this dataset, nearly all the survival findings were significant with a p-value of $<0.05$. Factors strongly linked to survival were insurance payer, race, and gender (Table 3). As expected, CCI, age and receipt of chemotherapy were linked to survival. Insurance status was a strong predictor of survival. When compared to patients with private insurance those without insurance or with medicaid had the poorest survival (risk ratio 1.44 and 1.42) followed by

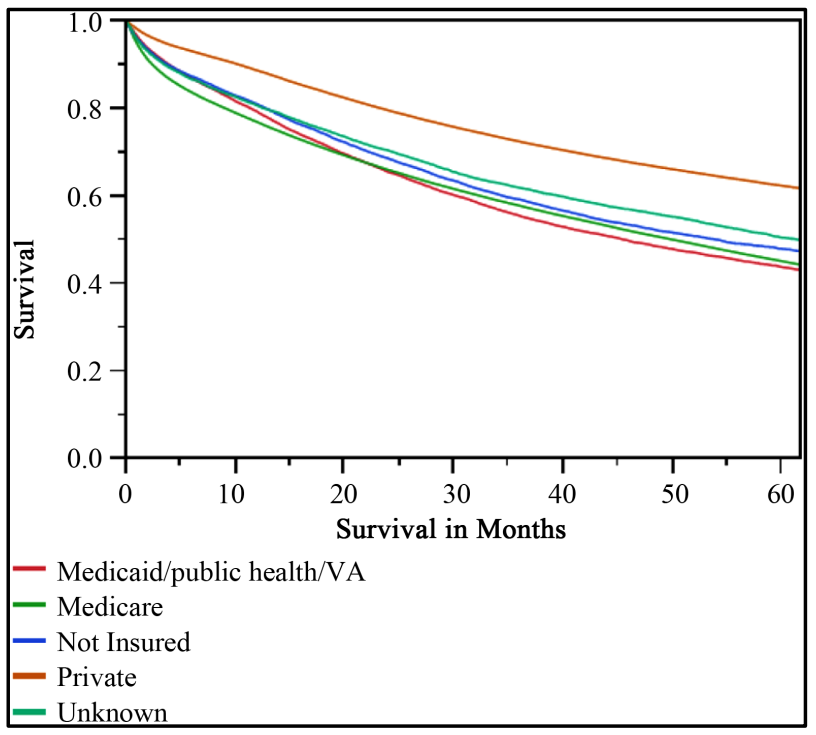

Figure 1. Association between survival and insurance payer for patients with colon cancer, NCDB 2003-2010.

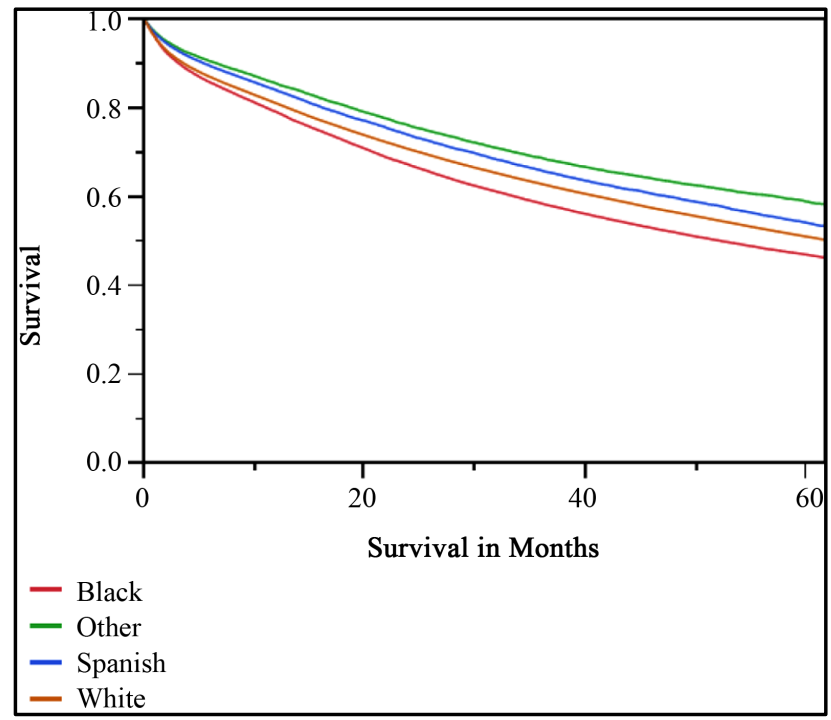

Figure 2. Survival by racial/ethnic group, NCDB 2003-2010. 
Table 3. Univariate and multivariate survival analysis for patients with colon cancer, NCDB 2003-2010.

\begin{tabular}{|c|c|c|c|c|c|}
\hline Factor & & Median survival (95\% CI) & $\mathrm{p}$ value & Risk ratio & $\mathrm{p}$ value \\
\hline \multirow[t]{9}{*}{ Location } & Atlantic & $61.8(60.7-62.8)$ & $<0.0001$ & $1.01(0.98-1.02)$ & 0.599 \\
\hline & Great lakes & $60.3(59.4-61.3)$ & & $1.05(1.04-1.07)$ & $<0.0001$ \\
\hline & Midwest & $62.2(60.6-63.7)$ & & $1.07(1.05-1.10)$ & $<0.0001$ \\
\hline & Mountain & $58.8(57.1-60.9)$ & & $1.10(1.06-1.12)$ & $<0.0001$ \\
\hline & Northeast & $64.3(63.1-65.9)$ & & $1.01(0.99-1.03)$ & 0.465 \\
\hline & Pacific & $70.8(69-72.5)$ & & 1 & \\
\hline & South & $61.3(59.7-63.1)$ & & $1.06(1.04-1.08)$ & $<0.0001$ \\
\hline & Southeast & $63.7(62.8-64.7)$ & & $1.04(1.03-1.06)$ & $<0.0001$ \\
\hline & West & $63.2(61.8-64.7)$ & & $1.06(1.04-1.09)$ & $<0.0001$ \\
\hline \multirow[t]{2}{*}{ Gender } & Male & $60.2(59.7-60.8)$ & $<0.0001$ & $1.11(1.10-1.12)$ & $<0.0001$ \\
\hline & Female & $65.8(65.3-66.5)$ & & 1 & \\
\hline \multirow[t]{4}{*}{ Insurance } & Medicare & $50.4(50-50.9)$ & $<0.0001$ & $1.11(1.09-1.12)$ & $<0.0001$ \\
\hline & Private & 98.7 (97.6 - 100.4) & & 1 & \\
\hline & Medicaid/public & $46.0(44.6-47.7)$ & & $1.44(1.41-1.48)$ & $<0.0001$ \\
\hline & Not insured & $54.4(52.2-57.3)$ & & $1.42(1.38-1.46)$ & $<0.0001$ \\
\hline Median county & $<30,000$ & $54.2(53.2-55.0)$ & $<0.0001$ & $1.06(1.04-1.08)$ & $<0.0001$ \\
\hline \multirow[t]{3}{*}{ Income } & $30,000-35,000$ & $57.4(56.6-58.2)$ & & $1.05(1.03-1.07)$ & $<0.0001$ \\
\hline & $35,000-45,999$ & $62.0(61.1-62.8)$ & & $1.02(1.01-1.03)$ & 0.0035 \\
\hline & $>45,000$ & $69.9(69.2$ - 70.6) & & 1 & \\
\hline High school & $<14 \%$ & $69.8(69.0$ - 70.6) & $<0.0001$ & 1 & \\
\hline \multirow[t]{4}{*}{ Dropout rate } & $14.4 \%-19.9 \%$ & $61.2(60.4-62.1)$ & & $1.05(1.04-1.07)$ & $<0.0001$ \\
\hline & $20-28.9$ & $58.9(58.0$ - 59.7) & & $1.07(1.05-1.09)$ & $<0.0001$ \\
\hline & $>29 \%$ & $57.1(56.2-58.1)$ & & $1.05(1.04-1.07)$ & $<0.0001$ \\
\hline & Unknown & $67.3(65.4-68.8)$ & & & \\
\hline \multirow[t]{3}{*}{ Population } & Metro & $63.5(63.0$ - 63.9) & $<0.0001$ & $1.03(0.99-1.06)$ & 0.1263 \\
\hline & Urban & $59.3(58.3-60.5)$ & & $1.01(0.98-1.05)$ & 0.483 \\
\hline & Rural & $57.5(54.8-60.7)$ & & 1 & \\
\hline \multirow[t]{3}{*}{ Charlson score } & 0 & $72.7(72.1-73.3)$ & $<0.0001$ & 1 & \\
\hline & 1 & $52.9(52.3-53.6)$ & & $1.22(1.21-1.23)$ & $<0.0001$ \\
\hline & $\geq 1$ & 31.7 (31.5 - 32.4) & & $1.70(1.67-1.72)$ & $<0.0001$ \\
\hline \multirow[t]{4}{*}{ Stage } & I & $100.5(100.6-102.6)$ & $<0.0001$ & 1 & \\
\hline & II & $84.9(84.1$ - 86.0) & & $1.55(1.53-1.58)$ & $<0.0001$ \\
\hline & III & $65.1(64.3-65.8)$ & & $3.14(3.09-3.19)$ & $<0.0001$ \\
\hline & IV & $13.6(13.5$ - 13.8) & & $11.41(11.23-11.61)$ & \\
\hline \multirow[t]{2}{*}{ Surgery } & Yes & $71.1(70.6$ - 71.5) & & 1 & \\
\hline & No & $6.7(6.5-6.8)$ & & $2.29(2.26-2.33)$ & $<0.0001$ \\
\hline \multirow[t]{2}{*}{ Chemotherapy } & No & $65.7(65.2-66.1)$ & $<0.0001$ & 1.96 & $<0.0001$ \\
\hline & Yes & $58.3(57.6-59.0)$ & & 1 & \\
\hline Age (decade) & & & & $1.35(1.35-1.36)$ & $<0.0001$ \\
\hline \multirow[t]{4}{*}{ Race } & White & $63.2(62.7-63.6)$ & $<0.0001$ & 1 & \\
\hline & African American & $53.0(51.9-54.1)$ & & $1.2(1.18-122)$ & $<0.0001$ \\
\hline & Hispanic & $70.9(68.0$ - 73.7) & & $0.93(0.91-0.95)$ & $<0.0001$ \\
\hline & Other & $88.8(84.8$ - 92.8) & & $0.87(0.84-0.89)$ & $<0.0001$ \\
\hline
\end{tabular}


medicare (risk ratio 1.1). Race was also liked to survival, but in an unexpected way. We found (with a model accounting for stage, insurance coverage and comorbidities) that Others and HS had a superior survival compared to NHWs. AAs had a $20 \%$ survival disadvantage. Women had superior survival than men. Socioeconomic status and location were weakly linked to survival. Low county level income and high school graduation rates were associated with diminished survival when compared to the highest level counties, risk ration 1.06 and 1.05.

\section{Discussion}

In order to adequately address the healthcare outcomes inequalities, we must clearly define which factors are associated with poorer outcomes. There are many studies associating healthcare outcome inequalities with race, socioeconomic status (SES), insurance coverage, population density and gender [4]. Although these data provide some understanding of healthcare inequality, conclusions are limited by an inability to control for key variables. Missing data elements include insurance payer status, treatment variables and comorbidities and the study of limited population (i.e. military, a single state, or $>65$ years old). In order to better define outcomes disparities, we embarked on an evaluation of the National Cancer Data Base (NCDB) which covers $70 \%$ of the newly diagnosed cancers in the United States and contains many variables missing from other data sets.

In this study we found that insurance payer was an important predictor of survival. Patients with medicaid or who were not insured had a more than $40 \%$ increased risk for mortality when compared to those with private insurance. In addition we found that race was strongly linked to survival, but in a way different from many previous studies. We found that, as most literature suggests, that African-Americans $(A A)$ are at a higher risk of mortality; we, however, found that Hispanics (HS) had a superior survival rate. Although socioeconomic and geographical factors were associated with survival, these associations were fairly weak.

Insurance payer status is strongly associated with survival for colorectal cancer. We found that patients who were uninsured or had medicaid/public insurance had a more than $40 \%$ increased risk for mortality when compared to those with private insurance. These data are an important extension of work done using the NCDB and other data sets. Ward demonstrated using data from the NCDB that patients who had medicaid or were uninsured presented more often with advanced colorectal cancer when compared to those with commercial insurance [23]. Robins, also with NCDB, found that survival was lower for patients with medicare or who uninsured compared to patients with private insurance [24]. In contrast to our data, the authors only looked at patients of age 18 64 years and follow-up was limited to one year. Similar studies using statewide registries have found that patients with colorectal cancer who were uninsured or had medicaid, had a higher risk of death compared to private insurance [20] [25] [26]. These studies, however, did not consistently adjust for SES or comorbidities. Gory found that the survival disadvantage associated with a lower ecologic SES was mitigated by access to health insurance [8]. Our data adds additional understanding to the role of health insurance as a mediator of outcome inequality for colon cancer as previous literature is limited by lack of controls for important confounding factors (SES, demographics and comorbidities), patient population, or inadequate follow-up.

We found little difference in survival between medicare patients and those with no insurance. The etiology of this is unclear but may be secondary to poor access to care for patients with medicaid insurance. Another contributor is enrollment after time of diagnosis. Many patients are enrolled in medicaid after diagnosis of cancer, as high as $45 \%$, and post-diagnosis enrollment is associated with a decreased survival [25] [27]. The NCDB does not allow us to distinguish between patients enrolled in medicaid at the time of diagnosis and those enrolled in medicaid after the diagnosis has been established.

Much of the survival disparities associated with colorectal cancer are diminished for patients who are cared for in an equal access medical system. Investigators have found that in the Veterans' Administration or military insured families, socioeconomic and racial factors have no or little influence on outcomes for patients with colorectal cancer [12] [14]. Comparisons between impoverished Canadian colon cancer patients and those in the US demonstrate improved quality, increased use of chemotherapy and better survival for Canadians [28] [29].

There is a significant body of literature on survival disparities in colorectal cancer for AAs. Multiple investigators have documented racial inequality in colorectal cancer, with diminished survival for AA patients [4] [6] [7] [9] [10] [21]. Similarly, we found on univariate analysis that AAs had a lower survival than any other group. This continued on multivariate analysis when controlling for stage, insurance status, comorbidity, and SES factors (Table 3).

There appears to be a paradox in survival for HS patients in this and other studies. We found that HS patients, 
as well as AA, were more likely to be un/under-insured, present with metastatic disease and living in regions of higher ecological socioeconomic deprivation. Despite this, on univariate and multivariate analysis it was found that HSs had a superior survival compared to AAs and Non-Hispanic Whites (NHW). This is similar to the findings of Phillips in the state of Texas [13]. In this study the authors report a decreased mortality for multiple cancers including colorectal. There are proposed mechanisms for this difference including a theory of selective migration of healthy immigrants and decreased smoking rates for HSs. The authors found that adjusting for smoking rates in a theoretical model accounted for differences in mortality for all cancers, including colorectal.

This study has several limitations. First, all socioeconomic data is ecologic, i.e., these data represent census track socioeconomic deprivation and not individual socioeconomic data. Also, we have access to only two socioeconomic factors limiting some of our ability to document socioeconomic deprivation. There are also limitations inherent to all large database studies. Secondary to the size of this database, many factors were statistically associated with survival even when the advantage was fairly modest. The readers need to be mindful of the clinical relevancies of these differences.

\section{Conclusion}

In conclusion, we found that insurance payer status was a stronger predictor of decrease survival than race or SES. These differences were noted on both univariate and multivariate analyses. These data indicate that access to care continues to be important beyond diagnosis. We also found that the AA race imparted about a $20 \%$ survival disadvantage compared to NHW. Finally, we also noticed a significant improvement in survival for HS Americans despite the presence of poor access to insurance, later stage of presentation and ecologic socioeconomic deprivation. The explanation for this paradox is not entirely clear, but may be related to healthy migration and smoking status.

\section{Consent}

Authors report no conflicts of interest relevant to this manuscript. Dr. Fitzgerald is on the speakers bureau for Genentech. All others have no financial disclosures, conflicts of interest, funding sources, and/or acknowledgements to report.

\section{References}

[1] Haider, A.H., Scott, V.K., Rehman, K.A., Velopulos, C., Bentley, J.M., Cornwell 3rd, E.E. and Al-Refaie, W. (2013) Racial Disparities in Surgical Care and Outcomes in the United States: A Comprehensive Review of Patient, Provider, and Systemic Factors. Journal of the American College of Surgeons, 216, 482-492. http://dx.doi.org/10.1016/j.jamcollsurg.2012.11.014

[2] Adler, N., Bush, N.R. and Pantell, M.S. (2012) Rigor, Vigor, and the Study of Health Disparities. Proceedings of the National Academy of Sciences of the United States of America, 109, 17154-17159. http://dx.doi.org/10.1073/pnas.1121399109

[3] Hellander, I. and Bhargavan, R. (2012) Report from the United States: The U.S. Health Crisis Deepens Amid Rising Inequality-A Review of Data, Fall 2011. International Journal of Health Services: Planning, Administration, Evaluation, 42, 161-175. http://dx.doi.org/10.2190/HS.42.2.a

[4] Fitzgerald, T.L., Bradley, C.J., Dahman, B. and Zervos, E.E. (2009) Gastrointestinal Malignancies: When Does Race Matter? Journal of the American College of Surgeons, 209, 645-652. http://dx.doi.org/10.1016/j.jamcollsurg.2009.08.007

[5] Bristow, R.E., Powell, M.A., Al-Hammadi, N., Chen, L., Miller, J.P., Roland, P.Y., Mutch, D.G. and Cliby, W.A. (2013) Disparities in Ovarian Cancer Care Quality and Survival According to Race and Socioeconomic Status. Journal of the National Cancer Institute, 105, 823-832. http://dx.doi.org/10.1093/jnci/djt065

[6] Soneji, S., Iyer, S.S., Armstrong, K. and Asch, D.A. (2010) Racial Disparities in Stage-Specific Colorectal Cancer Mortality: 1960-2005. American Journal of Public Health, 100, 1912-1916. http://dx.doi.org/10.2105/AJPH.2009.184192

[7] White, A., Vernon, S.W., Franzini, L. and Du, X.L. (2010) Racial Disparities in Colorectal Cancer Survival: To What Extent Are Racial Disparities Explained by Differences in Treatment, Tumor Characteristics, or Hospital Characteristics? Cancer, 116, 4622-4631. http://dx.doi.org/10.1002/cncr.25395

[8] Gorey, K.M., Luginaah, I.N., Holowaty, E.J., Zou, G., Hamm, C., Bartfay, E., Kanjeekal, S.M., Balagurusamy, M.K., Haji-Jama, S. and Wright, F.C. (2012) Effects of Being Uninsured or Underinsured and Living in Extremely Poor 
Neighborhoods on Colon Cancer Care and Survival in California: Historical Cohort Analysis, 1996-2011. BMC Public Health, 12, 897. http://dx.doi.org/10.1186/1471-2458-12-897

[9] Jinjuvadia, R., Jinjuvadia, K. and Liangpunsakul, S. (2013) Racial Disparities in Gastrointestinal Cancers-Related Mortality in the U.S. Population. Digestive Diseases and Sciences, 58, 236-243. http://dx.doi.org/10.1007/s10620-012-2312-3

[10] Phatak, U.R., Kao, L.S., Millas, S.G., Wiatrek, R.L., Ko, T.C. and Wray, C.J. (2013) Interaction between Age and Race Alters Predicted Survival in Colorectal Cancer. Annals of Surgical Oncology, 20, 3363-3369. http://dx.doi.org/10.1245/s10434-013-3045-z

[11] Singh, G.K., Williams, S.D., Siahpush, M. and Mulhollen, A. (2011) Socioeconomic, Rural-Urban, and Racial Inequalities in US Cancer Mortality: Part I-All Cancers and Lung Cancer and Part II-Colorectal, Prostate, Breast, and Cervical Cancers. Journal of Cancer Epidemiology, 2011, Article ID: 107497. http://dx.doi.org/10.1155/2011/107497

[12] Robinson, C.N., Balentine, C.J., Marshall, C.L., Anaya, D.A., Artinyan, A., Awad, S.A., Albo, D. and Berger, D.H. (2010) Ethnic Disparities Are Reduced in VA Colon Cancer Patients. American Journal of Surgery, 200, 636-639. http://dx.doi.org/10.1016/j.amjsurg.2010.07.020

[13] Philips Jr., B.U., Belasco, E., Markides, K.S. and Gong, G. (2013) Socioeconomic Deprivation as a Determinant of Cancer Mortality and the Hispanic Paradox in Texas, USA. International Journal for Equity in Health, 12, 26. http://dx.doi.org/10.1186/1475-9276-12-26

[14] Andaya, A.A., Enewold, L., Zahm, S.H., Shriver, C.D., Stojadinovic, A., McGlynn, K.A. and Zhu, K. (2013) Race and Colon Cancer Survival in an Equal-Access Health Care System. Cancer Epidemiology, Biomarkers \& Prevention: A Publication of the American Association for Cancer Research, 22, 1030-1036.

[15] Lee, W., Nelson, R., Mailey, B., Duldulao, M.P., Garcia-Aguilar, J. and Kim, J. (2012) Socioeconomic Factors Impact Colon Cancer Outcomes in Diverse Patient Populations. Journal of Gastrointestinal Surgery: Official Journal of the Society for Surgery of the Alimentary Tract, 16, 692-704. http://dx.doi.org/10.1007/s11605-011-1809-y

[16] Bradley, C.J., Given, C.W., Dahman, B. and Fitzgerald, T.L. (2008) Adjuvant Chemotherapy after Resection in Elderly Medicare and Medicaid Patients with Colon Cancer. JAMA Internal Medicine, 168, 521-529. http://dx.doi.org/10.1001/archinternmed.2007.82

[17] Coleman Wallace, D.A., Baltrus, P.T., Wallace, T.C., Blumenthal, D.S. and Rust, G.S. (2013) Black White Disparities in Receiving a Physician Recommendation for Colorectal Cancer Screening and Reasons for Not Undergoing Screening. Journal of Health Care for the Poor and Underserved, 24, 1115-1124. http://dx.doi.org/10.1353/hpu.2013.0132

[18] Dorsey, K., Zhou, Z., Masaoud, R. and Nimeiri, H.S. (2013) Health Care Disparities in the Treatment of Colorectal Cancer. Current Treatment Options in Oncology, 14, 405-414. http://dx.doi.org/10.1007/s11864-013-0241-9

[19] Grubbs, S.S., Polite, B.N., Carney Jr., J., Bowser, W., Rogers, J., Katurakes, N., Hess, P. and Paskett, E.D. (2013) Eliminating Racial Disparities in Colorectal Cancer in the Real World: It Took a Village. Journal of Clinical Oncology: Official Journal of the American Society of Clinical Oncology, 31, 1928-1930. http://dx.doi.org/10.1200/JCO.2012.47.8412

[20] Niu, X., Roche, L.M., Pawlish, K.S. and Henry, K.A. (2013) Cancer Survival Disparities by Health Insurance Status. Cancer Medicine, 2, 403-411. http://dx.doi.org/10.1002/cam4.84

[21] Robbins, A.S., Siegel, R.L. and Jemal, A. (2012) Racial Disparities in Stage-Specific Colorectal Cancer Mortality Rates from 1985 to 2008. Journal of Clinical Oncology: Official Journal of the American Society of Clinical Oncology, 30, 401-405. http://dx.doi.org/10.1200/JCO.2011.37.5527

[22] Raval, M.V., Bilimoria, K.Y., Stewart, A.K., Bentrem, D.J. and Ko, C.Y. (2009) Using the NCDB for Cancer Care Improvement: An Introduction to Available Quality Assessment Tools. Journal of Surgical Oncology, 99, 488-490. http://dx.doi.org/10.1002/jso.21173

[23] Ward, E., Halpern, M., Schrag, N., Cokkinides, V., DeSantis, C., Bandi, P., Siegel, R., Stewart, A. and Jemal, A. (2008) Association of Insurance with Cancer Care Utilization and Outcomes. CA: A Cancer Journal for Clinicians, 58, 9-31. http://dx.doi.org/10.3322/CA.2007.0011

[24] Robbins, A.S., Pavluck, A.L., Fedewa, S.A., Chen, A.Y. and Ward, E.M. (2009) Insurance Status, Comorbidity Level, and Survival among Colorectal Cancer Patients Age 18 to 64 Years in the National Cancer Data Base from 2003 to 2005. Journal of Clinical Oncology: Official Journal of the American Society of Clinical Oncology, 27, 3627-3633. http://dx.doi.org/10.1200/JCO.2008.20.8025

[25] Koroukian, S.M., Bakaki, P.M. and Raghavan, D. (2012) Survival Disparities by Medicaid Status: An Analysis of 8 Cancers. Cancer, 118, 4271-4279. http://dx.doi.org/10.1002/cncr.27380

[26] Halpern, M.T., Ward, E.M., Pavluck, A.L., Schrag, N.M., Bian, J. and Chen, A.Y. (2008) Association of Insurance Status and Ethnicity with Cancer Stage at Diagnosis for 12 Cancer Sites: A Retrospective Analysis. The Lancet Oncology, 9, 222-231. http://dx.doi.org/10.1016/S1470-2045(08)70032-9 
[27] Bradley, C.J., Given, C.W. and Roberts, C. (2003) Late Stage Cancers in a Medicaid-Insured Population. Medical Care, 41, 722-728. http://dx.doi.org/10.1097/01.MLR.0000065126.73750.D1

[28] Gorey, K.M., Holowaty, E.J., Fehringer, G., Laukkanen, E., Moskowitz, A., Webster, D.J. and Richter, N.L. (1997) An International Comparison of Cancer Survival: Toronto, Ontario, and Detroit, Michigan, Metropolitan Areas. American Journal of Public Health, 87, 1156-1163. http://dx.doi.org/10.2105/AJPH.87.7.1156

[29] Gorey, K.M., Luginaah, I.N., Bartfay, E., Fung, K.Y., Holowaty, E.J., Wright, F.C., Hamm, C. and Kanjeekal, S.M. (2011) Effects of Socioeconomic Status on Colon Cancer Treatment Accessibility and Survival in Toronto, Ontario, and San Francisco, California, 1996-2006. American Journal of Public Health, 101, 112-119. http://dx.doi.org/10.2105/AJPH.2009.173112 
Scientific Research Publishing (SCIRP) is one of the largest Open Access journal publishers. It is currently publishing more than 200 open access, online, peer-reviewed journals covering a wide range of academic disciplines. SCIRP serves the worldwide academic communities and contributes to the progress and application of science with its publication.

Other selected journals from SCIRP are listed as below. Submit your manuscript to us via either submit@scirp.org or Online Submission Portal.
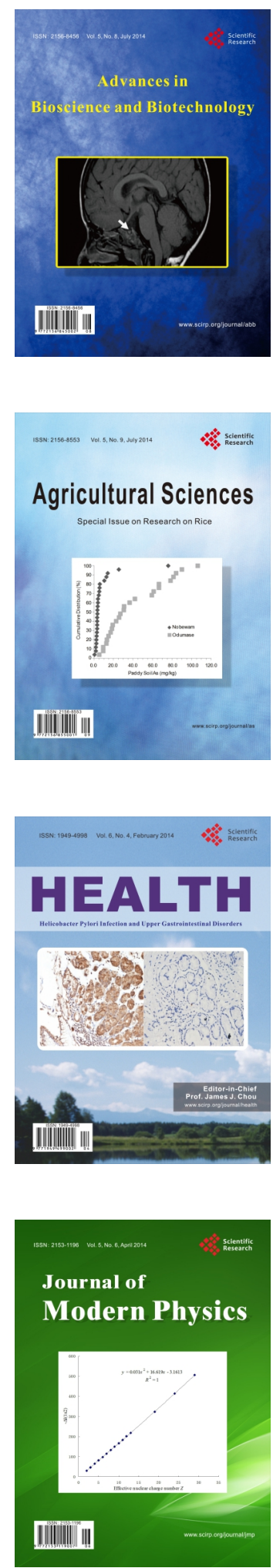
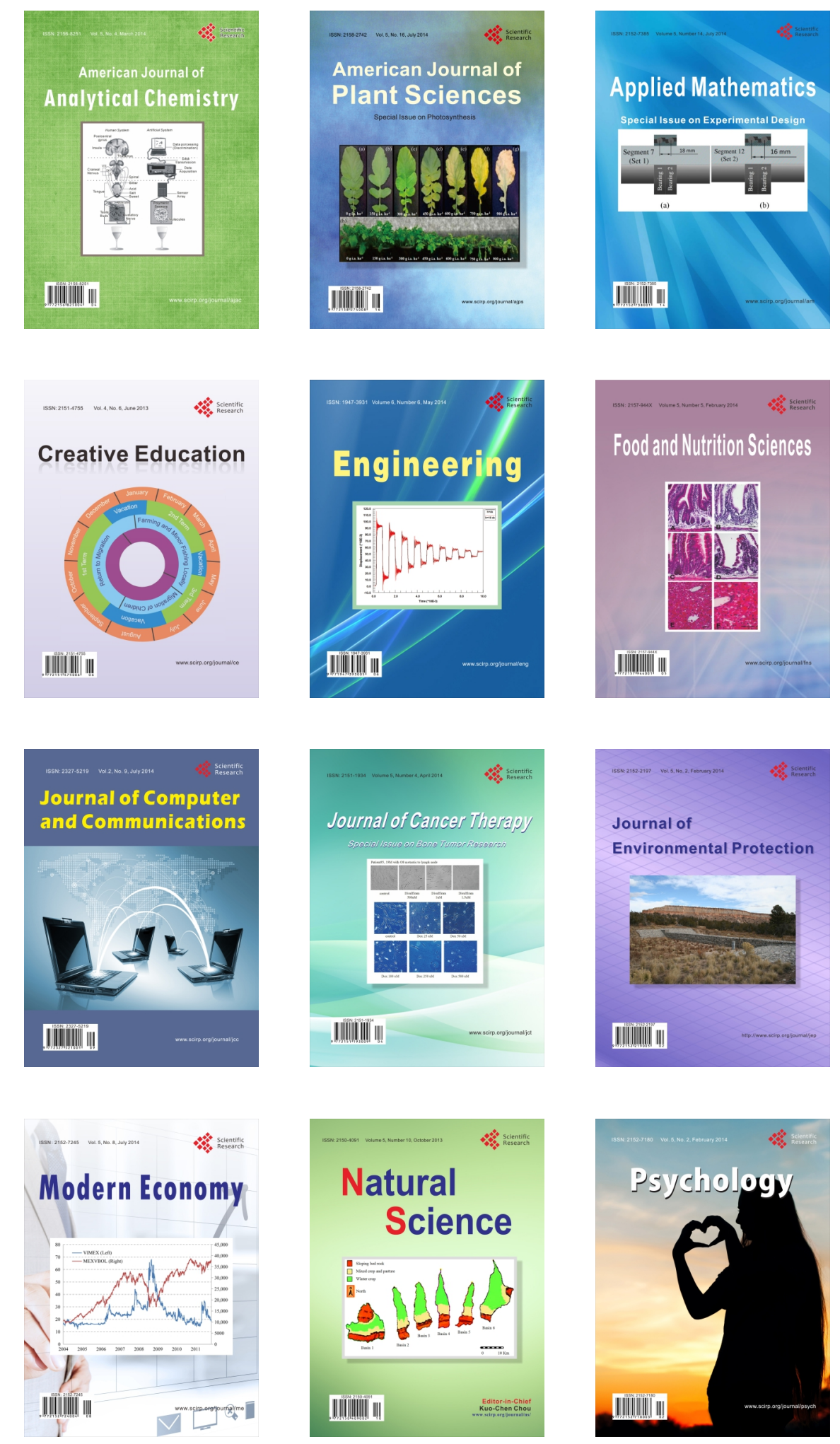